\title{
Study on adsorption of phosphate from aqueous solution by nanomaterial $\mathrm{CeO}_{2}$
}

\author{
Dao Hong Duc ${ }^{1,4}$, Dao Ngoc Nhiem ${ }^{2 *}$, Nguyen Quang Bac ${ }^{2}$, Do Quang Trung ${ }^{3}$ \\ ${ }^{I}$ Graduate University of Science and Technology, Vietnam Academy of Science and Technology \\ ${ }^{2}$ Institute of Materials Science, Vietnam Academy of Science and Technology \\ ${ }^{3}$ Department of Chemistry, Hanoi University of Science, Vietnam National University \\ ${ }^{4}$ Bac Bo Water Resource College
}

Received 28 December 2016; Accepted for publication 28 August 2017

\begin{abstract}
The synthesis of nanosize single phase $\mathrm{CeO}_{2}$ by gelatine gel combustion method was investigated. The prepared material was characterized by $\mathrm{X}$ - ray diffraction, thermogravimetric and differential thermal analysis, scanning electron microscopy and transmission electron microscopy measurements. At optimum conditions, such as $\mathrm{pH} 3$, the molar ratio of $\mathrm{Ce}^{4+} /$ gelatine $1 / 1$, and a calcination temperature of $550{ }^{\circ} \mathrm{C}$ for 2 hours, the material with average size $<30 \mathrm{~nm}$ was synthesized. From the results of phosphate adsorption, adsorption equilibrium time of the material was determined at 60 minutes. The phosphate adsorption process in aqueous solution followed the Langmuir isothermal model with $\mathrm{Q}_{\max }=$ $152.66 \mathrm{mg} / \mathrm{g}$.
\end{abstract}

Keywords. $\mathrm{CeO}_{2}$, gelatine, combustion method, phosphate $\left(\mathrm{PO}_{4}{ }^{3-}\right)$ adsorption.

\section{INTRODUCTION}

Currently, the excessive use of chemicals in agriculture has been the cause of contaminated water with fluoride, phosphate, ammonium... In the aqueous environment, the excess of phosphate cause extensive eutrophication, all kinds of algae, moss. Algae growth leads to massive changes to ecosystems and environmental conditions. Phosphate residues or excess in the body both are dangerous poison to the human body such as osteoporosis (because calcium can react with phosphate) and clogged blood vessels leading to stroke or heart attack leading or heart failure [1]. So, the treatment of phosphate in the water is needed now, in order to reduce environmental pollution, ensure people's living environment. There are methods of treatment of phosphate in the aquatic environment including biological and chemical methods.

Biological methods are the use of some microorganisms to accumulate more phosphorus in the body than we need. Many of the microorganisms involved in the process of absorption - storage disposal, the microorganisms, in general, is called bio-P microbial groups that microorganisms are primarily Acinetobacter. Biological methods are environmentally friendly, but besides that these methods depend on environmental conditions and the composition of pollutants in the wastewater. Because each type of microorganisms living in different conditions and the impact of pollution components on them are different. On the other hand, the processing time by this method is relatively long.

To overcome the limitations of biological methods while ensuring the handling of phosphate in water, chemical methods are prospective promise solutions. The chemical method in handling phosphate in particular or pollutant, in general, is not dependent on external conditions and the impact of pollution indices, short processing time, ease to desorption. The most important factor in the chemical method is a synthesis of materials.

The chemical methods are being applied in the manufacture of materials including co-precipitation techniques, sol-gel, hydrothermal technique. These are classics, controllable to synthesized the morphology and the chemical composition of the materials. The advantage of these methods is that improved uniformity and high specific surface area of the material lead to increase their activity $[2,3,6$, $8,10-12]$.

On the other hand, oxide $\mathrm{CeO}_{2}$ is widely applied 
in various fields such as cerium catalytic exhaust treatment, solar batteries, fluorescent materials, and UV adsorption [2-5]. In this paper, the adsorption of phosphate anions from the solution will be studied by using $\mathrm{CeO}_{2}$ nanomaterials synthesized by sol-gel with gelatine.

\section{EXPERIMENTAL}

\subsection{Chemicals}

All agents were analytical grade including $\mathrm{Ce}\left(\mathrm{NO}_{3}\right)_{4}, \quad$ gelatine, $\mathrm{Na}_{3}\left(\mathrm{PO}_{4}\right), \quad\left(\mathrm{NH}_{4}\right)_{2} \mathrm{MoO}_{4}$, $\mathrm{NH}_{4} \mathrm{VO}_{3}, \mathrm{HCl}, \mathrm{NaOH}$ were purchased from SigmaAldrich and Merck.

\subsection{Synthesis}

Weight an amount of gelatin and put into $30 \mathrm{ml}$ of distilled water and continuously stirr at $80{ }^{\circ} \mathrm{C}$ with a magnetic stirrer until gelatine is completely dissolved, add slowly an amount of $\mathrm{Ce}^{4+}$ solution to the gel with a molar ratio $\mathrm{Ce}^{4+} /$ gelatine $1 / 1, \mathrm{pH} 3$. The mixture was kept stirring to obtain a colorless transparent gel. After 4 hours dried out at $110{ }^{\circ} \mathrm{C}$, a part of the sample was analyzed by the thermal analysis method, the rest products were calcinated at $180,450,550$ and $650{ }^{\circ} \mathrm{C}$ during 2 hours.

\subsection{Characterization}

The products obtained during different stages were characterized by X-ray diffraction (XRD) using D8Advance - Bruker diffractometer with $\mathrm{CuK \alpha}$ radiation $(\lambda=0.15406 \AA)$ in the range of $2 \theta=10^{\circ}$ $95^{\circ}$, and a scanning rate of $0.02^{\circ} \mathrm{s}^{-1}$. The micromorphology of the nanomaterial was evaluated by field emission scanning electron microscopy (FESEM) by Hitachi S-4800 microscope (Japan) and transmission electron microscopy (TEM) by JEOL JEM-1010 (Japan). Thermal analysis (TGA-DTA) of the gel precursors was carried out on a Setaram Labsys EVO (France) from room temperature to 850 ${ }^{\circ} \mathrm{C}$ in the air with a heating rate of $10^{\circ} \mathrm{min}^{-1}$.

The concentration of $\mathrm{PO}_{4}{ }^{3-}$ was determined by the photometric colorimetric method by the UV1800 Shimadzu spectrophotometer (Japan) using ammonium molybdate/vanadate according to ISO 5815:2008 [7].

Assessment of $\mathrm{PO}_{4}{ }^{3-}$ adsorption capacity from the solution follows the Langmuir adsorption isotherm model. The maximum adsorption capacity and isothermal constants are determined by regression. The correlation between the experimental data of $\mathrm{PO}_{4}{ }^{3-}$ concentration remaining in solution $\left(\mathrm{C}_{\mathrm{f}}, \mathrm{mg} / \mathrm{l}\right)$ under saturated adsorption capacity $(\mathrm{q}, \mathrm{mg} / \mathrm{g})$ was treated on Table Curves calculation software.

Langmuir adsorption isotherm was successfully applied in many adsorption processes of pollutants and the most widely used to describe the process of adsorption of solutes from the solution according to the Langmuir equation of the form:

$$
q=\frac{Q \max \cdot b \cdot C f}{1+b \cdot C f}
$$

Where: $\mathrm{Q}_{\max }$ : The maximum adsorption capacity on the monolayer surface $(\mathrm{mg} / \mathrm{g})$; q: Adsorption capacity $(\mathrm{mg} / \mathrm{g})$; b: Isothermal constants $\left(\mathrm{dm}^{3} / \mathrm{mg}\right)$; $\mathrm{C}_{\mathrm{f}}$ : The phosphate remaining concentration $(\mathrm{mg} / \mathrm{l})$.

\section{RESULTS AND DISCUSSION}

\subsection{Preparation and characterization of materials}

\subsubsection{TG-DTA curves}

The thermal analysis results of Ce-gelatine gel samples were recorded in figure 1. As can be seen from the figure 1 , there are two discrete weight losses.

+ The first major weight loss $(55.90 \%)$ at temperatures below $200{ }^{\circ} \mathrm{C}$ which accompanied by a peak at $185^{\circ} \mathrm{C}$ on the DTA curve due to dehydration of water in the gel samples.

+ The second effect with $34.45 \%$ of weight loss occurred in the temperature range of $200-475{ }^{\circ} \mathrm{C}$, reduced volume due to the decomposition of gelatin gel. Corresponds to the effects on the DTA curve at $460{ }^{\circ} \mathrm{C}$ are the formation of $\mathrm{CeO}_{2}$ and the burning of some residual precursors or intermediate formed during the formation of $\mathrm{CeO}_{2}$. When the temperature is higher than $500{ }^{\circ} \mathrm{C}$, it almost does not see any weight loss or peaks on the DTA, it proves the stabilization of the nano $\mathrm{CeO}_{2}$.

\subsubsection{XRD diagrams}

From the results of the thermal analysis as the basis for selection of gel calcination temperature, the sample was annealed at different temperatures of $180,450,550$ and $650{ }^{\circ} \mathrm{C}$ for 2 hours. The analytical results of the samples were recorded by XRD method in figure 2 .

It can be clearly seen from the XRD diagram, the figure shows that the sample heated at $180{ }^{\circ} \mathrm{C}$ have no specific peak of the single phase. This especially agrees with the TG analysis results above. 


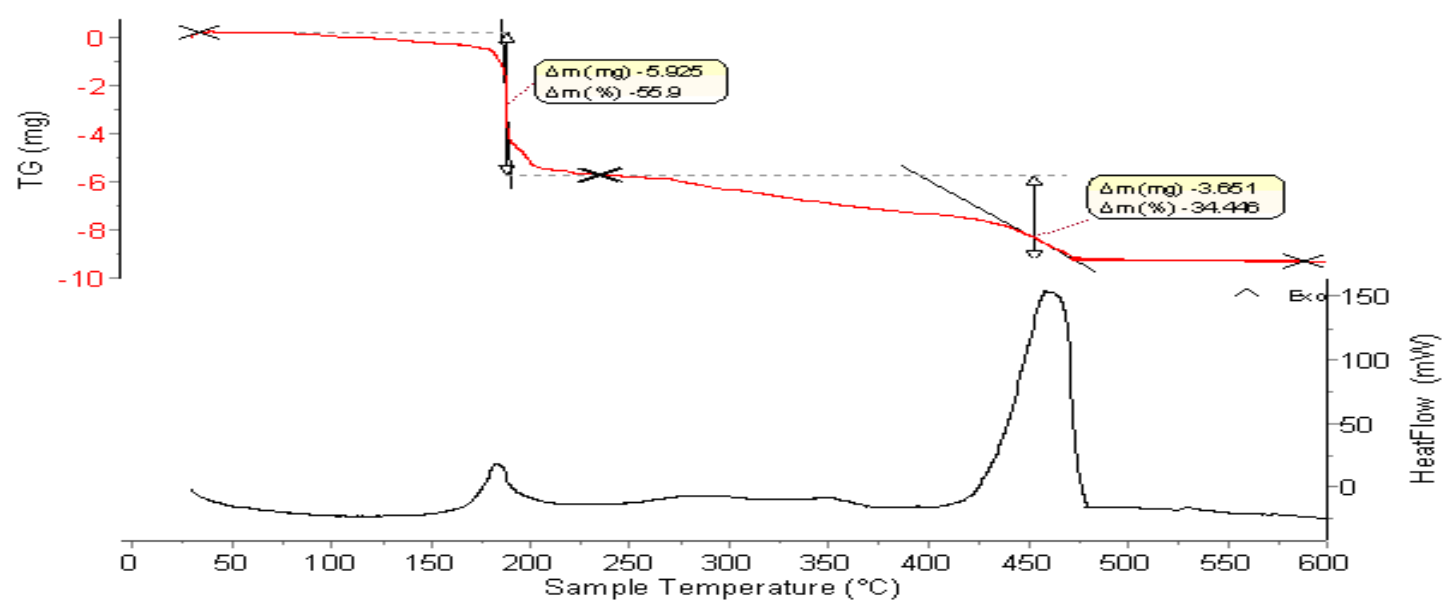

Figure 1: TG-DTA curve of the Ce-gelatin gel sample

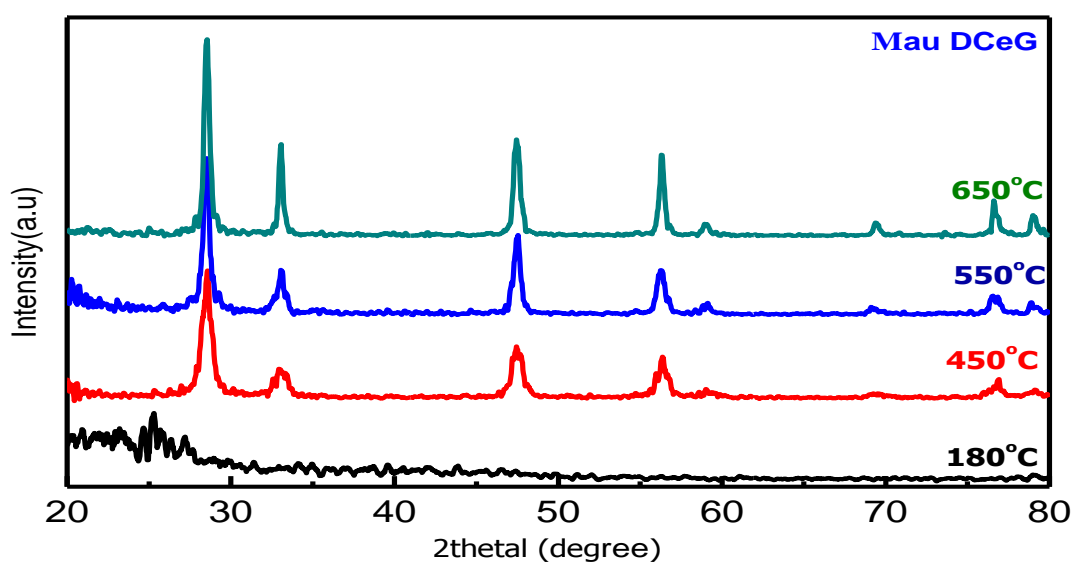

Figure 2: XRD diagrams of samples calcined at $180,450,550$, and $650{ }^{\circ} \mathrm{C}$

Calcined samples from 200 to $350{ }^{\circ} \mathrm{C}$ were almost no mass loss on the TG curve (Fig. 1). So, no phase formation of $\mathrm{CeO}_{2}$ which similar to the study [3]. When samples are calcined at higher temperatures: 450,550 and $650{ }^{\circ} \mathrm{C}$, there were the characteristic reflection peaks for the formation of $\mathrm{CeO}_{2}$ single crystalline phase.

The results showed that increasing of calcination temperature created the crystalline phase of $\mathrm{CeO}_{2}$. Calcination temperature has affected the formation of $\mathrm{CeO}_{2}$ phase. To comparison with gel-PVA combustion method, the forming of $\mathrm{CeO}_{2}$ single phase occurred at $100{ }^{\circ} \mathrm{C}$ lower by gel-gelatine [3]. This is a positive sign for to preparing materials using gel-gelatine combustion method. It can be a scientific basis for further studies on the use of gelatin to other synthetic materials.

\subsubsection{SEM and TEM images}

Characteristic morphology and size of the nanopowders $\mathrm{CeO}_{2}$ surface were recorded on SEM and TEM images (figure 3). The FE-SEM and TEM showed particles of relatively uniform size range < $30 \mathrm{~nm}$. Particles have cavity structure which similar to the study [3].

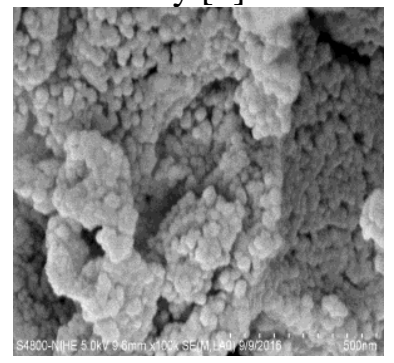

(a)

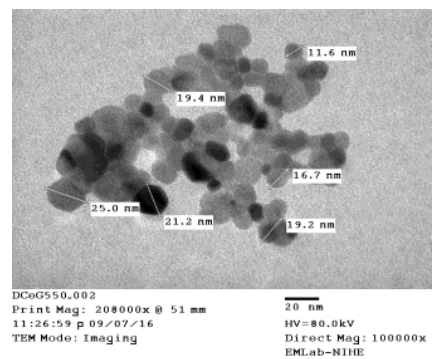

(b)
Figure 3: FE-SEM (a) and TEM (b) images of the sample

\section{2. $\mathrm{PO}_{4}{ }^{3-}$ adsorption capacity of nano $\mathrm{CeO}_{2}$}

\subsubsection{Adsorption equilibrium time}

To investigate the adsorption equilibrium time of $\mathrm{PO}_{4}{ }^{3-}$ by $\mathrm{CeO}_{2}$ nanoparticle, a series of experiments were conducted as follows: add $0.05 \mathrm{~g}$ of the material $\mathrm{CeO}_{2}$ into $100 \mathrm{~mL} \mathrm{PO}_{4}{ }^{3-}$ solution with 
concentration $10 \mathrm{mg} / \mathrm{l}$, stir constantly by magnetic stirrer for different reaction time, sampling every 30 minutes to analyze the remaining phosphate concentration. The analytical results and calculations are recorded in table 1 .

Table 1: Effect of reaction time of the phosphate adsorption by nanomaterial $\mathrm{CeO}_{2}$

\begin{tabular}{|c|c|c|c|c|}
\hline $\mathrm{t}(\min )$ & $\begin{array}{c}\mathrm{C}_{0} \\
(\mathrm{mg} / \mathrm{l})\end{array}$ & $\begin{array}{c}\mathrm{C}_{\mathrm{f}} \\
(\mathrm{mg} / \mathrm{l})\end{array}$ & $\begin{array}{c}\mathrm{q} \\
(\mathrm{mg} / \mathrm{g})\end{array}$ & $\begin{array}{c}\text { Adsorption } \\
\text { efficiency } \\
\mathrm{H}(\%)\end{array}$ \\
\hline 30 & 10 & 5.52 & 8.96 & 44.80 \\
\hline 60 & 10 & 3.72 & 12.57 & 62.85 \\
\hline 90 & 10 & 3.85 & 12.30 & 61.50 \\
\hline 120 & 10 & 4.50 & 11.00 & 55.00 \\
\hline
\end{tabular}

Table 1 shows that the adsorption capacity $\mathrm{PO}_{4}{ }^{3-}$ increased over time, $\mathrm{PO}_{4}{ }^{3-}$ adsorption capacity of the material reached the highest value in a period of 60 minutes to 90 minutes, while the adsorption capacity tended to decrease when the time increased to 120 minutes. The adsorption performance decreases at 120 minutes compared to 90 minutes because the process of adsorption is the reversible process. The adsorption capacity is greatest at the adsorption equilibrium time. When prolonged adsorption causes a part adsorbed substance was eluted. Therefore, the adsorption equilibrium time of the materials is 60 minutes, it was chosen as a condition of following studies.

\subsection{2. $\mathrm{PO}_{4}{ }^{3-}$ adsorption capacity by nanomaterial $\mathrm{CeO}_{2}$}

$\mathrm{PO}_{4}{ }^{3-}$ adsorption capacity was evaluated in similar experiments to the previous part with a solution $\mathrm{PO}_{4}{ }^{3-}$ concentrations ranging from 5 to $180 \mathrm{mg} / \mathrm{l}$. Results analysis and calculations are shown in figure 4 .

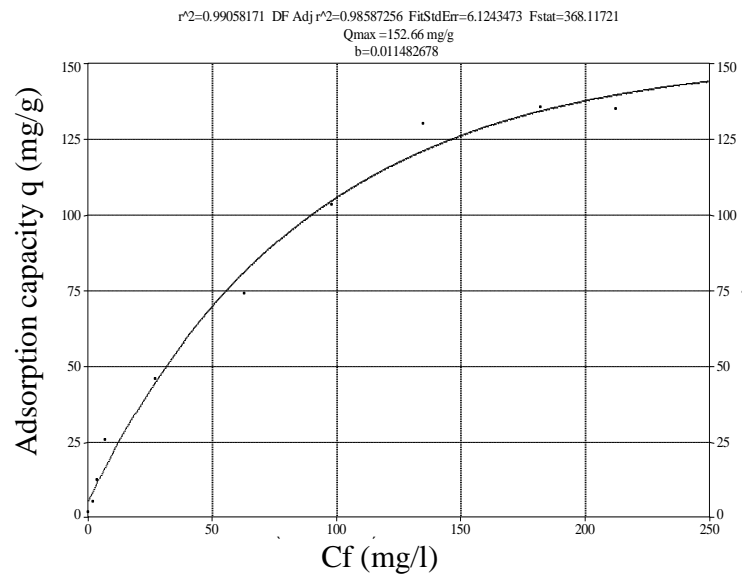

Figure 4: Langmuir adsorption isothermal of phosphate by the nanomaterials $\mathrm{CeO}_{2}$
From the experimental results, obtained $\mathrm{Q}_{\max }=$ $152.66 \mathrm{mg} / \mathrm{g}$ by using regression calculated software Table - the curve of experimental results. The phosphate adsorption of nanoparticle $\mathrm{CeO}_{2}$ materials with Qmax $=152.66 \mathrm{mg} / \mathrm{g}$ and regression coefficient $r^{2}=0.99$. The results are well described by the Langmuir isotherm adsorption coefficient with regression $r=0.99$.

\section{CONCLUSION}

Synthesized nanomaterials $\mathrm{CeO}_{2}$ have average size < $30 \mathrm{~nm}$ by gel combustion method using gelatin, under conditions: molar ratio of $\mathrm{Ce}^{4+} /$ gelatin is $1 / 1$, the gelling temperature of $80{ }^{\circ} \mathrm{C}, \mathrm{pH} 3$ and calcination temperature at $550{ }^{\circ} \mathrm{C}$ for 2 hours. The phosphate adsorption capacity from the solution of nanomaterials $\mathrm{CeO}_{2}$ also was fully conducted as follows: adsorption equilibrium time of the nanomaterials is 60 minutes and the maximum adsorption capacity of the nanomaterials $\mathrm{CeO}_{2}$ is $152.66 \mathrm{mg} / \mathrm{g}$ with regression $\mathrm{r}^{2}=0.99$.

\section{REFERENCES}

1. Phuong Thao, Do Quang Trung, Dang Thi Thu Huong, Cong Tien Dung. Research by lanthanum modifiedlaterite material treatment fluoride ion adsorption and phosphate in wastewater, Vietnam Journal of Chemistry, 54(3) 356-361(2016)

2. Recillas S., Colón J., Casals E., González E., Puntes V., Sánchez A., Font X. Chromium VI Adsorption on Cerium Oxide Nanoparticles and Morphology Changes during the Process. J. Hazard. Mater., 184 (1-3), 425-431 (2010).

3. Luu Minh Dai, Nguyen Gia Hung, Vo Quang Mai, Dao Ngoc Nhiem. Low temperature synthesisof nanostructured cerium dioxide by auto combustion process of polyvinyl alcohol-cerium nitrate gel. Vietnam Journal of Chemistry, 42(4), 444-448 (2004).

4. Luu Minh Dai, Dao Ngoc Nhiem, Nguyen Van Phu, Duong Thi Lim. Synthesis of nanostructured of $\mathrm{CeO}_{2}-\mathrm{Al}_{2} \mathrm{O}_{3}$ by combustion method, Vietnam Journal of Chemistry, 49(4), 405-408 (2011).

5. Dao Ngoc Nhiem,Luu Minh Dai, Nguyen Duc Van, Duong Thi Lim. Catalytic oxidation of carbon monoxide over nanostructured $\mathrm{CeO}_{2}-\mathrm{Al}_{2} \mathrm{O}_{3}$ prepared by combustion method using polyvinyl alcohol, J. Ceramics International, 39, 3381-3385 (2013).

6. Bui Van Thang, Le Ba Thuan. An investigation of phosphorus adsorption capacity by modified bentonite: effect of ph, concomitant anion and adsorption mechanism. Vietnam Journal of Chemistry, 51(3AB), 407-412 (2013).

7. Vietnam Organization for Standardization 5815:2001. NPK fertilizer-Test Method, (2008). 
8. Hui Deng, Xili Yu. Adsorption of fluoride, arsenate and phosphate in aqueous solution by cerium impregnated fibrous protein, Chemical Engineering Journal, 184, 205-212 (2012).

9. Liu Chang - jiun, Li Yan-zhong et al. Adsorption removal of phosphate from aqueous solution by active red mud, Journal of Environmental Science, 19, 1166-1170 (2007).

10. Contreras A. R., García A., González E., Casals E., Puntes V., Sánchez A., Font, X. Recillas S. Potential Use of $\mathrm{CeO}_{2}, \mathrm{TiO}_{2}$ and $\mathrm{Fe}_{3} \mathrm{O}_{4}$ Nanoparticles for the
Removal of Cadmium from Water, Desalin. Water Treat, 41(1-3), 296-300 (2012).

11. Recillas S., García A., González E., Casals E., Puntes V., Sánchez A., Font X. Use of $\mathrm{CeO}_{2}, \mathrm{TiO}_{2}$ and $\mathrm{Fe}_{3} \mathrm{O}_{4}$ Nanoparticles for the Removal of Lead from Water. Toxicity of Nanoparticles and Derived Compounds. Desalination, 277(1-3), 213-220 (2011).

12. Yin S., Minamidate Y., Tonouchi S., Goto T., Dong Q., Yamane, Sato T. Solution synthesis of homogeneous plate-like multifunctional $\mathrm{CeO}_{2}$ particles, RSC Advances, 2, 5976-5982 (2012).

\section{Corresponding author: Dao Ngoc Nhiem}

Institute of Materials Science

Vietnam Academy of Science and Technology

No. 18, Hoang Quoc Viet Road, Cau Giay Dist., Hanoi

E-mail: nhiemdn@ims.vast.ac.vn; Telephone: 0466747816. 